\title{
田
}

\section{ANTE À RADICALIZAÇÃO HETERO-PATRIARCAL: RESISTÊNCIAS E POSSIBILIDADES ÉTICO-POLÍTICAS NO SERVIÇO SOCIAL}

\author{
AGAINST TO HETERO-PATRIARCHAL RADICALIZATION: RESISTANCE AND ETHICAL-POLICY \\ POSSIBILITIES IN SOCIAL SERVICE
}

\author{
Poliana Machado Gomes da Silva* \\ https://orcid.org/0000-0001-8220-6229
}

\begin{abstract}
RESUMO
Considerando-se o recrudescimento do conservadorismo hetero-patriarcal na sociabilidade brasileira, este artigo tem como objetivo central identificar as resistências e possibilidades ético-políticas do Serviço Social no antagonismo ao ultraconservadorismo hetero-patriarcal estruturante das relações sociais no Brasil. Para tanto, realizou-se uma pesquisa do tipo teórica e documental, e, utilizou-se as técnicas de coleta de dados, tais como a pesquisa bibliográfica e a pesquisa documental. Por meio de uma análise materialista histórica e dialética, verificou-se que somente quando se apreende o real é que se pode transformá-lo. Por esse ângulo, as entidades representativas do Serviço Social brasileiro (CFESS-CRESS, ABEPSS e ENESSO) buscam materializar e viabilizar o direcionamento ético-político profissional no cotidiano de suas ações, uma vez que reconhecem e se propõem contrárias às formas de dominação, exploração e opressão sexistas, patriarcais e homo-lebo-bi-trans-fóbicas. É irrefutável, portanto, que a direção ético-política da profissão é materializada, sobretudo, a partir de campanhas, seminários temáticos, movimentos estudantis, conferências, resoluções e, em especial, através da articulação com os movimentos feministas e da incorporação de seus anseios.
\end{abstract}

\section{PALAVRAS-CHAVE}

Hetero-Patriarcado. Serviço Social. Ultraconservadorismo.

\section{ABSTRACT}

Considering the resurgence of hetero-patriarchal conservatism in brazilian sociability, this article aims to identify the resistances and ethical-political possibilities of Social Service in the antagonism to structural hetero-patriarchal ultraconservatism of social relations in Brazil. Therefore, a theoretical and documentary research was carried out, and data collection techniques were used, such as bibliographic research and documentary research. Through a historical and dialectical materialist analysis, it was found that only when one apprehends the real can one transform it. From this angle, the representative entities of the Brazilian Social Work (CFESS-CRESS, ABEPSS and ENESSO) seek to materialize and enable the professional ethicalpolitical direction in the daily routine of their actions, since they recognize and propose contrary to the forms of domination, exploitation and sexist, patriarchal, and homo-lebo-bi-transphobic oppression. It is undeniable, therefore, that the ethical-political direction of the profession is materialized above all through

\footnotetext{
* Assistente social. Mestranda em Serviço Social, Trabalho e Questão Social pela Universidade Estadual do Ceará. (UECE, Fortaleza, Brasil). Av. Dr. Silas Munguba, 1700 - Itaperi, Fortaleza (CE), CEP.: 60714-903. E-mail: $<$ polly.mach@hotmail.com>.
}

DOI 10.22422/temporalis.2019v19n38p148-163

\section{(cc) BY} Commons Atribuição 4.0 Internacional (https://creativecommons.org/licenses/by/4.o/deed.pt_BR), que permite copiar e redistribuir o material em qualquer suporte ou formato, bem como adaptar, transformar e criar a partir deste material para qualquer fim, mesmo que comercial. O licenciante não pode revogar estes direitos desde que você respeite os termos da licença.

Temporalis, Brasília (DF), ano 19, n. 38, p. 180-195, jul./dez. 2019. | ISSN 2238-1856 
campaigns, thematic seminars, student movements, conferences, resolutions and, in particular, through the articulation with feminist movements and the incorporation of their aspirations.

\section{KEYWORDS}

Hetero-Patriarchy. Social Service. Ultraconservative.

\section{INTRODUÇÃO}

6 - $\begin{array}{r}\text { E viado fei", "A mundiça ainda tá de calcinha", "Vão matar o viado". Estas foram } \\ \text { frases oralizadas pelos assassinos da travesti Dandara dos Santos, em } 2017 \text { na } \\ \text { cidade de Fortaleza (CE). "Depois de levar pontapés na cabeça e ser espancada por }\end{array}$ um enorme pedaço de madeira, ela foi levada por um carrinho de mão como se fosse um saco de lixo para sua morte, completamente ensanguentada" (ANDRADE, 2017, não paginado). O assassinato contra Dandara foi transfobia e não homofobia. Em 2018, no centro do Rio de Janeiro, a vereadora Marielle Franco (PSOL) e o motorista Anderson Pedro Gomes foram assassinados a tiros. Marielle saía do evento Jovens negras movendo a estrutura e ao chegar próximo à prefeitura da cidade, "[...] um carro emparelhou com o veículo, atirou inúmeras vezes e acelerou em fuga" (PITASSE, 2018, não paginado). O assassinato de Marielle foi feminicídio e não homicídio.

Sob uma pretensa ausência ideológica, o conservadorismo é intrínseco das ideologias presentes na luta de classes, mas não só. Além de não apresentar uma coerência interna e nem realizar autocrítica, o conservadorismo é uma expressão ideo-política e cultural superdimensionada quando em sua articulação às relações hetero-patriarcais de gênero, raça/etnia e classe social. Infelizmente, a realidade brasileira aponta que entre os anos de 2016 e início de 2017, São Paulo e Bahia ${ }^{1}$ foram analisados como os estados nacionais, respectivamente, que mais cometem homicídios à população de Lésbicas, Gays, Bissexuais, Travestis, Transexuais e Transgêneros (LGBT)². O Ceará, por seu turno, tornou-se, em 2017, o quarto estado brasileiro que mais mata gays, travestis e transexuais, sendo o Brasil o país que mais mata travestis e transexuais no mundo, e, o quinto país mais violento contra as mulheres 3 .

Ademais, nos fins do ano de 2018 e início de 2019, sinalizam-se várias investidas ultraconservadoras a nível nacional. Em 2019, o ministro da Educação, Ricardo Vélez Rodríguez, faz algumas declarações, como: "Quem define gênero é a natureza"4. A atual ministra da Mulher, da Família e dos Direitos Humanos, Damares Alves, advoga uma afirmação carregada de conteúdo moralizante e ideológico: "Menino veste azul e menina veste rosa"' . Por fim, Jair Messias Bolsonaro, o atual presidente da República brasileira adverte em seu discurso de posse que vai: "[...] combater a ideologia de gênero, conservando nossos valores. O Brasil voltará a ser um país livre de amarras ideológicas" (UOL, 2019, não paginado).

\footnotetext{
${ }^{1}$ Sobre, ver $\mathrm{G}_{1}$ (2017).

${ }^{2}$ Utilizar-se-á neste artigo o termo LGBT, em decorrência da utilização da sigla em documentos oficiais, como as políticas sociais brasileiras, as conferências e os seminários realizados para essa população, em níveis nacional e internacional, e, por sua frequência nos escritos teóricos acadêmicos.

3 Para mais, ver Senado Notícias (2018).

4 Para mais, ver Pavaneli (2018).

${ }^{5}$ Para mais, ver Pains (2019).
}

Temporalis, Brasília (DF), ano 19, n. 38, p. 180-195, jul./dez. 2019. | ISSN 2238-1856 


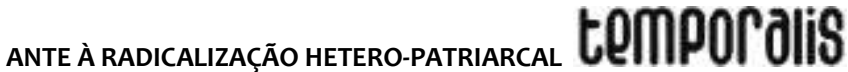

Diante desse cenário, é preciso ter explícito que os/as assistentes sociais não estão imunes a esse caldo ultraconservador. Em que pese tais ingerências, a direção ético-política do Serviço Social, consolidada na década de 1990, é nítida: toma-se a liberdade como valor ético central, com um posicionamento intransigente em relação à defesa dos direitos humanos, respeitando-se a diversidade humana. Nada obstante, a materialização dessa direção ético-política necessita de sujeitos profissionais que se identifiquem e se comprometam com a mesma. Em uma palavra: a competência ético-política do Serviço Social não se materializa sem os/as sujeitos profissionais com ela comprometidos/as, assegurando uma identidade profissional. Estes três posicionamentos ético-políticos, vinculados e imbricados dialeticamente aos demais princípios éticos profissionais, possibilitam o estabelecimento de uma ponte para o reconhecimento, afirmação e defesa da diversidade sexual e de gênero.

Sob essa ótica, traçar caminhos em prol da pluralidade sexual e de gênero é uma das tarefas ético-políticas do Serviço Social. À luz do materialismo histórico e dialético, esta investigação objetiva, a partir de uma pesquisa do tipo teórica e documental, e, das técnicas de coleta de dados pesquisa bibliográfica e pesquisa documental, identificar as resistências e possibilidades ético-políticas do Serviço Social antagônicas ao recrudescimento do conservadorismo hetero-patriarcal estruturante das relações sociais no Brasil. Além de campanhas, seminários temáticos, movimentos estudantis, conferências e articulação com os movimentos feministas, foram analisadas as resoluções CFESS/CRESS que conferem materialidade à direção ético-política do Serviço Social ante à radicalização hetero-patriarcal.

\section{RELAÇÕES HETERO-PATRIARCAIS DE GÊNERO E CONSERVADORISMO}

É propondo fidedignidade ao dado da realidade, que esta pesquisa se propõe científica. Todavia, é sempre cabível a afirmação de que "[...] toda realidade é sempre muito mais rica e complexa do que a possibilidade de compreensão, análise e explicação que se faça sobre esta" (OSTERNE; BRASIL; ALMEIDA, 2013, p. 158). A realidade, assim posta, é saturada de determinações. Para conhecê-la e explorar seus determinantes, nuanças, contradições, particularidades e singularidades, esta pesquisa lança mão de sucessivas aproximações, visando-se a reprodução ideal do movimento da realidade, do objeto de estudo. Esta investigação, sob o enfoque do método marxiano de análise, situa e analisa os fenômenos sociais num complexo e contraditório processo de produção e reprodução, inseridos numa totalidade concreta: a sociabilidade burguesa.

É no tempo e no espaço e no espaço da edificação da sociedade burguesa que se assiste à emergência do pensamento conservador na Europa Ocidental (ESCORSIM NETTO, 2011). Como expressão cultural vinculada aos interesses da nobreza fundiária e do alto clero, o conservadorismo, em seu movimento clássico (entre os séculos XVI e XVIII), exprime oposição à cultura da Modernidade que favoreceu o corroer das estruturas sociais e instituições feudais, bem como o deslocamento das visões de mundo até então imperantes (ESCORSIM NETTO, 2011).

Inicialmente, como classe revolucionária, a burguesia ascende politicamente como classe dominante. Aproximadamente entre os anos de 1830 e 1848, quando se evidencia o 
esgotamento do ciclo revolucionário da burguesia, a cultura moderna experimente uma crise político-ideológica. Soma-se a este processo um movimento de refuncionalização do pensamento conservador, objetivando "[...] eliminar ou neutralizar os conteúdos subversivos da cultura moderna, especialmente aqueles vinculados à sua dimensão emancipadora" (ESCORSIM NETTO, 2011, p. 47). Numa perspectiva contrarrevolucionária, são construídas as bases para uma relação entre o pensamento conservador e o pensar burguês em antagonismo à ameaça revolucionária socialista.

A largos passos, tem-se uma apropriação do conservadorismo pelo modo de produzir e reproduzir relações capitalistas. A reprodução das relações sociais capitalistas incorpora o pensamento conservador para a reprodução da totalidade da vida social, o que engloba não somente a reprodução da vida material, mas também a reprodução espiritual da sociedade, de seus modos de consciência social pelos quais as pessoas se posicionam na vida social. Por conseguinte, a reprodução social é a reprodução de um certo modo de vida, da forma como se reproduzem as ideias e pensares, do cotidiano, de princípios e valores, de práticas culturais e políticas que permeiam a trama das relações sociais.

Conforme Lima Sobrinho e Lima (2018), os conservadores acreditam que "[...] os indivíduos têm necessidades inalteráveis que são: a ordem, a religião, a tradição, a família e a segurança" (LIMA SOBRINHA; LIMA, 2018, p. 31). Falseando a história, capitalismo e conservadorismo lançam mão de ideologias anti-transformação para a reprodução de modos de ser necessários à sua legitimação. Desse modo, o pensamento conservadorismo, apesar de divergentes posicionamentos conservadores, defende a imutabilidade da sociedade, das estruturas sociais e, no limite, dos corpos e das mentes dos indivíduos.

Em antagonismo ao que é defendido pelo conservadorismo, os indivíduos são, neste artigo, entendidos como sujeitos históricos, simultaneamente seres singulares e seres genéricos, não detendo uma essência, aprioristicamente definida e isolada das relações sociais. À vista disso, o ato de individuar-se supera a existência simplesmente singular como um membro da espécie humana, porque, na construção da individualidade, agregamse, desenvolvem-se e potencializam-se qualidades e conquistas históricas. A diversidade humana, assim, "[...] articula-se à concepção de indivíduo social como uma característica própria da individuação” (CISNE; SANTOS, 2018, p. 28).

Não restam dúvidas de que os indivíduos se tonam diversos em face de diversas questões, tais como: o estilo de vida, as determinações de classe, os aspectos referentes à raça/etnia, à orientação sexual, à identidade de gênero, etc. Os indivíduos se desenvolvem, portanto, "[...] da simples singularidade, como expressão muda do gênero humano, para a individualidade, e de modo crescente e contínuo desencadeia sua substância, que é a formação da personalidade e da consciência" (CISNE; SANTOS, 2018, p. 33). Embora muitos/as teóricos/as realizem críticas ao arsenal teórico-metodológico marxista, disseminadas no âmbito acadêmico e no contexto político, advogando não ser possível no universo da tradição marxista apreender a dimensão da individualidade, esta tradição vem rejeitando as modalidades simplistas do economicismo, do politicismo, do culturalismo e do eticismo na análise do papel da consciência e do desenvolver do indivíduo na história.

Nessa esteira analítica, ressalta-se a consubstancialidade e coextensividade presente nas 


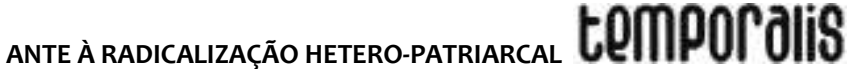

relações sociais de gênero, raça/etnia e classe social ${ }^{6}$. As aspas aqui postas se dão em defesa da categoria gênero como útil para análise das relações hetero-patriarcais. Isto porque alguns estudos marxistas e, sobretudo, materialistas francófonos, optam pelo termo relações sociais de sexo, acreditando que gênero é uma palavra polissêmica, o que o leva a uma concepção vaga ou incerta, de caráter essencialmente neutro, genérico e, talvez, a-histórico.

Acredita-se que a categoria relações sociais de sexo contribui não somente para dar nitidez ao antagonismo constituído a partir das relações sociais entre homens e mulheres. Todavia, utilizar-se-á neste artigo a categoria relações hetero-patriarcais de gênero. Logo, gênero pode até ser uma categoria guarda-chuva, por abarcar a diversidade dos gêneros, no entanto, é uma categoria que torna visíveis os sujeitos desviantes da binariedade homem/mulher e que são, cotidianamente, oprimidos e explorados face às relações hetero-patriarcais7, sexistas, racistas e capitalistas.

Sendo a sexualidade o conjunto dos processos sociais que produzem e organizam a expressão do desejo e o gozo dos prazeres corporais orientados a sujeitos (FOUCAULT, 1988), as relações patriarcais de gênero sinalizaram um modelo ideal de vida sexual para a diversidade humana. A saber: o modelo heterossexual, o qual aparece, no decurso histórico das relações sexuais, como o modelo padrão, ideal para avaliação de todas as outras sexualidades. Como se fosse uma determinação biológica, a heterossexualidade é naturalizada pelas relações patriarcais de gênero, normatizando e ordenando o modo pelo qual os sujeitos vivenciam e expressam a sua sexualidade ou não. Nessas circunstâncias, na sociabilidade do capital, a diversidade humana é, então, posta em xeque pelas relações hetero-patriarcais de gênero imbricadas na dinâmica das relações étnico-racial e de classe. À produção e reprodução sociais, nessa formação social, cabe a função de assegurar a manutenção e da perpetuação dos interesses heteropatriarcal-racista-capitalista. Efetuamse, para tanto, relações sociais que, via de regra, lançam mão das diferenças biológicas para se justificarem.

O heterossexismo em consonância com o patriarcado, é para Cisne e Santos (2018, p. 44), "[...] uma forma ideológica de naturalização dos sexos que organiza, estrutura e dissemina a heterossexualidade como a prática supostamente correta e única possibilidade aceitável de expressão e vivência afetivo-sexual”. Sem embargo, a ideologia dominante é a “[...] expressão ideal das relações materiais dominantes [...]; portanto, das relações que precisamente tornam dominante uma classe, portanto as ideias do seu domínio" (MARX; ENGELS, 2009, p. 67). A título de ilustração, a ideologia conservadora, apropriada pela lógica do capital, expressa com clareza a divisão sexual e racial do trabalho, a defesa da família monogâmica cis-heteropatriarcal, a LGBTfobia, o sexismo, o racismo, etc.

\footnotetext{
${ }^{6}$ Enquanto relações consubstanciais e coextensivas, as mesmas encontram-se imbricadas em um nó indissociável. Tais relações, contudo, só podem ser dissociadas através da análise sociológica, mas nunca ao nível das práticas sociais.

7 A palavra patriarcado, segundo Christine Delphy (2009), advém da combinação das palavras gregas “[...] pater (pai) e arke (origem e comando)" (DELPHY, 2009, p. 174). O patriarcado é literalmente a autoridade paterna. Portanto, "[...] designa uma formação social em que os homens detêm o poder, ou ainda, mais simplesmente, o poder é dos homens. Ele é, assim, quase sinônimo de 'dominação masculina' ou de opressão das mulheres" (DELPHY, 2009, p. 173).
} 
Penetrando na consciência dos indivíduos, a ideologia conservadora, patriarcal-racistacapitalista busca naturalizar as relações de dominação, opressão e exploração produzidas pela alienação. O discurso ideológico da Natureza, de determinismo biológico, é movido por leis mecânicas naturais, imutáveis, místico-naturais. Logo, jamais movem esse discurso as leis sociais e histórico-dialéticas. A saída dessa ideologia Natural, para tanto, não se fará sem a destruição total do sistema dominante de produção e reprodução hetero-patriarcalracista-capitalista.

\section{FEMINISMOS, HETERO-PATRIARCADO E A CONSOLIDAÇÃO DO NOVO ETHOS PROFISSIONAL DO SERVIÇO SOCIAL}

A questão social, objeto de estudo e trabalho dos/as assistentes sociais, expressa tanto as desigualdades quanto as rebeldias (IAMAMOTO, 2015). Aqui é possível indicar que a questão social é corolário necessário do modo de produção capitalista. Ela acompanha o capitalismo desde sua gênese e se desenvolve junto com ele, ganhando novas configurações, mas sempre arrimada no antagonismo de classe que baseia esse sistema. Logo, divergentes estágios capitalistas exigem diferentes manifestações ou expressões da questão social. À vista disso, a questão social remete ao conjunto das expressões e ressonâncias das desigualdades não só referentes às classes sociais, mas também aos gêneros, às raças/etnias, às sexualidades, etc., pois a questão social se configura à medida em que o composto das desigualdades (sociais, econômicas e culturais) transparecem politicamente por artifício das classes mais populares. É no âmbito das resistências, face a essas desigualdades, que se situam os movimentos feministas e o Serviço Social.

No século passado, manifesta-se no Brasil o denominado feminismo mal-comportado. Neste, articulavam-se às teses feministas as teses comunistas e as anarquistas, apontando como questão central, diversas vezes, a exploração do trabalho. Confrontando poderes, o feminismo mal-comportado ou mal-criado expressava o enfrentamento ao patriarcado, estruturante e estruturador das relações sociais no Brasil. Com a ditadura militar engendrada em 1964 pela autocracia burguesa, até a década de 1970, as feministas passaram a integrar a luta em sua oposição, protagonizando o movimento pela anistia e democracia, ainda que muitas mulheres tenham sido presas e, inclusive, torturadas. É na dinâmica conjuntural dos anos 1960, face a emergência de diversos movimentos libertários nacionais ${ }^{8}$, que o Serviço Social irá se aproximar dos movimentos sindicais e sociais, dentre eles, os movimentos feministas e movimento de mulheres. Isto porque o cenário econômico e sócio-político brasileiro forneceu elementos para a contestação do Serviço Social tradicional.

As condições que corroboraram para uma erosão do Serviço Social tradicional tiveram as suas bases gestadas desde os anos 1950, no seio da crise do padrão de desenvolvimento capitalista. Mundialmente, os anos 1960 sinalizaram diversas manifestações de protestos com diferentes reivindicações de cunho político-econômico e ideocultural. O Serviço Social e outras tantas profissões não ficaram imunes a essa efervescência. A pretensa neutralidade do Serviço Social foi questionada. Num movimento de renovação, demandouse a laicização profissional. No período que antecede o golpe de 1964, possibilitou-se o

\footnotetext{
8 Exemplos de alguns desses movimentos libertários são: aqueles vinculados à Igreja Católica (as Comunidades Eclesiais de Base, a Ação Popular, a Juventude Universitária Católica e a Juventude Operária Católica); e, aqueles articulados à Educação Popular (o Movimento de Educação de Base).
} 


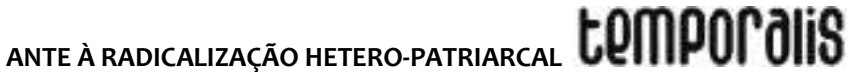

questionamento dos pressupostos e valores metafísicos de cariz neotomista, mas sem romper com certos valores liberais e de base funcionalista.

Nada obstante, com o golpe de abril em 1964, a ditadura coloca "[...] condições novas [...] para as práticas, as modalidades de reprodução e as (auto) representações profissionais" (NETTO, 2015, p. 155). Introduzia-se, no contexto de modernização conservadora, valores liberais que possibilitaram uma reformulação ética do Código de Ética de 1947. Aquelas condições novas irão ferir o Serviço Social, em especial, em dois níveis imbricados: o da sua prática e o da sua formação profissional, ambos transversais à legitimação de um novo ethos profissional, legalizado pelo Código de Ética de 1965.

Em nome do bem-comum e da justiça, as referências liberais do Código de 1965 são suprimidas. Como uma expressão da reatualização do conservadorismo, elabora-se e configura-se o Código de Ética de 1975. É salutar apontar também que, mesmo com as constrições ditatoriais, é elaborado o Método Belo Horizonte (Método BH) entre 1972 e 1975, sinalizando a perspectiva de intenção de ruptura com o conservadorismo da profissão. Inácio (2013) aponta a existência de uma identificação teórico-política do Método BH com algumas tendências feministas marxistas da época. Todavia, o Método BH foi restrito aos muros acadêmicos e, num contexto repressivo marcado pelo Al-5 (19681974), não foi possível uma articulação com os movimentos feministas e de mulheres de esquerda.

A autocracia burguesa, mesmo freando o movimento de renovação do Serviço Social, mas não o pondo em inércia, não conseguiu suprimir as disputas entre projetos profissionais nos fins da década de 1970. A partir da segunda metade desta década, construía-se um espaço unitário de resistência contra a ditadura militar. Envolveram-se, nesse processo, movimentos sindicais, estudantis, intelectuais e artísticos, movimentos de mulheres e LGBT. Num cenário de resistência às expressões da questão social, tanto o Serviço Social brasileiro quanto o movimento feminista se articularam em torno de um empreendimento comum: a redemocratização da sociabilidade brasileira.

De norte a sul do país, a partir da segunda metade dos anos 1970, os/as assistentes sociais passaram a indagar os valores e princípios no interior de seus discursos, de suas elaborações teóricas e de sua prática. É emblemática, nesse período, a realização, em setembro de 1979, do denominado "Congresso da Virada" ou III Congresso Brasileiro de Assistentes Sociais (CBAS). Massivamente e coletivamente, a categoria profissional manifesta a erupção do projeto de intenção de ruptura com o tradicionalismo ou conservadorismo ético-político, teórico-metodológico e técnico-operacional do Serviço Social.

A década de 1980 assinala para o Serviço Social a descaracterização legalista de valores e princípios presentes nos Códigos de Ética anteriores do Serviço Social (1947, 1965, 1976). Resultado de um amplo processo de trabalho conjunto, de organização da categoria profissional, de aproximação do Serviço Social com as ciências sociais, movimentos sociais e com a tradição marxista, tem-se a construção de um novo ethos profissional em 1986. Diante disso, “[...] a dimensão política da profissão foi explicitada de forma objetiva, como processo que exigia uma nova ética e um comprometimento com as necessidades e os 
interesses dos usuários do Serviço Social: a classe trabalhadora" (BARROCO; TERRA, 2012, p. 47). Dito isso, a nova ética buscou na tradição marxista a superação do tratamento ahistórico, a-crítico e abstratos dos valores profissionais legitimados na trajetória profissional. Além do mais, Maria Lúcia Barroco e Sylvia Terra (2012) trazem algumas conquistas efetivadas com o Código de Ética de 1986:

[...] o rompimento com a pretensa perspectiva 'imparcial' dos Códigos anteriores; o desvelamento do caráter político da intervenção ética; a explicitação do caráter de classe dos usuários, antes dissolvidos no conceito abstrato de 'pessoa humana'; a negação de valores a-históricos; a recusa do compromisso velado ou explícito com o poder instituído (BARROCO; TERRA, 2012, p. 48).

Tais conquistas não estão apartadas da conjuntura de democratização gestada na sociedade brasileira. Na confluência da luta pela anistia democrática e pelas eleições diretas, o Serviço Social passa a se envolver com o composto das classes populares e da tradição marxista. A dinamização dos movimentos feministas marxistas e socialistas contribuiu, segundo Inácio (2013), para uma “[...] primeira aproximação do Serviço Social ao feminismo, uma vez que a profissão também passa a incorporar a tradição marxista" (INÁCIO, 2013, p. 138).

Assim, apesar de avanços significativos em relação ao Serviço Social e sua aproximação com os feminismos marxista e socialista, a profissão findou por se alimentar teóricometodologicamente de fontes marxistas enviesadas. Dito de outro modo, o Serviço Social, em sua virada ética, teórica e prática, não bebeu das fontes originais do pensar marxiano, mas sim de intérpretes que nem sempre foram fiéis ao pensar de Marx. É o "[...] marxismo sem Marx, [...], sem uma sustentação ontológico-dialética, cheio de contaminação positivista (epistemologismo), em que se opera a combinação do formalismo ao empirismo" (INÁCIO, 2013, p. 134).

Ocorreu que, num cenário de enfrentamento ao modelo de Estado neoliberal, projetos profissionais foram postos em disputa. Barroco e Terra (2012) apontam que, de um lado, estavam profissionais que visavam preservar as conquistas materializadas em 1986; por outro lado, haviam profissionais que pretendiam a sua regressão. Com disputas internas à profissão, há uma reformulação, em 1993, do Código de Ética de 1986, permitindo a partir dos anos 1990, a inserção dos debates feministas na categoria profissional. Para Inácio (2013):

O debate feminista ingressa de forma mais ampla no Projeto Ético-Político do Serviço Social nos anos 1990, por meio da adoção da expressão "gênero", o que pode ser observado na literatura profissional, nos instrumentos normativos da profissão, como o Código de Ética (1993) e as Diretrizes Curriculares (1996) e na organização política da categoria. A introdução do debate feminista sob a ótica do "gênero" ocorre no momento em que a profissão aprofunda o debate sobre ética, marxismo e Serviço Social, sob a influência de autores marxistas do porte de Gramsci (1891-1937) e especialmente Lukács (1885-1971) (BARROCO; TERRA, 2012, p. 142-143).

O posicionamento ético-político expresso, sobretudo, nos Código de Ética e projeto profissional demarca a sintonia do Serviço Social com os anseios feministas que objetivam eliminar as desigualdades entre homens e mulheres. Torna-se hegemônico, nesse sentido, um projeto profissional que, sendo ético e político, está estreitamente vinculado a um 


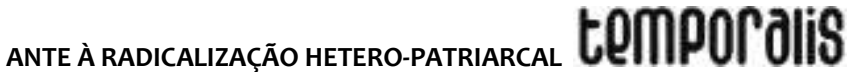

projeto macroscópico de sociedade. Os projetos societários se fazem presentes na dinâmica dos projetos coletivos, inclusive na dinâmica do Projeto Ético-Político (PEP) do Serviço Social, podendo, a grosso modo, ser transformadores ou conservadores. O PEP, consolidado e tornado hegemônico na década de 1990), vincula-se a um projeto de transformação social, dado o próprio dimensionamento político posto pela intervenção profissional entrelaçada por uma valoração ética específica.

A incorporação dos estudos sexuais e de gênero pelo Serviço Social data, assim, da década de 1990. É sabido que se, por um lado, "[...] a discussão sobre relações de gênero não está ausente do campo do Serviço Social, sabe-se, por outro que há muito ainda a ser amadurecido em relação ao tema" (INÁCIO, 2013, p. 186). Algo é certo: o direcionamento ético-político do Serviço Social, elucidado em especial nas bases normativas do Código de Ética de 1993, afirma: a liberdade como valor ético central; a defesa intransigente dos direitos humanos; a equidade e justiça social; o "Empenho na eliminação de todas as formas de preconceito, incentivando o respeito à diversidade, à participação de grupos socialmente discriminados e à discussão das diferenças" (BARROCO; TERRA, 2012, p. 128); a garantia do pluralismo teórico-metodológico; a opção por um projeto profissional vinculado a um projeto societário sem dominação-exploração de classe, raça/etnia e gênero; e, um exercício profissional sem ser discriminado, nem discriminar.

Algo, no entanto, deve ser lembrado: os princípios e valores norteadores desse projeto, definidos por escolhas coletivas da categoria profissional e condicionados por determinantes históricos mais abrangentes, colidem com os pilares e sustentáculos da ordem do capital. Isso não quer dizer que os/as assistentes sociais no cotidiano de suas práticas, diante do movimento histórico contemporâneo ultraconservador que impera desafios reais à viabilização do PEP, não materializem a direção ético-política. Pelo contrário, somente quando se apreende o real é que se pode transformá-lo.

\section{DECISÕES DE ORDEM ÉTICO-POLÍTICA DO SERVIÇO SOCIAL DIANTE DO ULTRACONSERVADORISMO HETERO-PATRIARCAL}

O ultraconservadorismo, compreendido nesta pesquisa como uma expressão heterogênea de diversas formas tradicionais, de mecanismos e de meios de reatualização do conservadorismo moral, ideopolítico, cultural e teórico, ameaça, assim, a materialização da dimensão ético-política do Serviço Social. Além desta, diversos são os elementos postos em xeque: a direção marxiano-marxista; a liberdade como valor ético central; a defesa intransigente dos direitos humanos; a oposição às formas de exploração e opressão de classe, gênero e raça/etnia; defesa de um projeto alternativo de sociedade; respeito à diversidade sexual e de gênero; apoio aos movimentos sociais.

Pautados em valores universais, no humanismo, na ideia de progresso histórico, na razão moderna, os projetos profissionais emancipatórios findam por serem desclassificados pelo recrudescimento do conservadorismo. Prima-se, nos moldes da conjuntura brasileira, pelo estímulo ao individualismo exacerbado, oculta-se a luta antagônica de classes, disseminase uma série de mitos: da igualdade racial, da igualdade sexual e de gênero, pelo simples motivo da existência de um/a conhecido/a ou colega negro/a e/ou LGBT. Ao lançar mão dos mitos, a apologética capitalista visa bloquear a compreensão das relações hetero- 
patriarcais de gênero, de raça/etnia e de classe, almeja confundir os referenciais ideopolíticos e teóricos das ações sociopolíticas emancipatórias.

Numa sociabilidade de raízes racistas, hetero-patriarcais, conservadoras e autoritárias como a brasileira, a ideologia das classes dominantes executa uma função de enfrentamento das tensões sociais. Num esforço de preservar a ordem social nos momentos em que eclodem os antagonismos sociais, falseia-se a história, incita-se a população às práticas fascistas, naturaliza-se a violência, legitima-se a repressão, criminalizam-se os movimentos sociais, a pobreza, os feminismos, a diversidade humana. Internaliza-se na vida cotidiana o medo social. Num estado de insegurança, a segurança se faz com intolerância, numa cruzada ao que é adverso, ao que se desvia dos princípios e preceitos da sociedade hetero-patriarcal-racista-capitalista.

Em que pese os pilares hetero-patriarcais impressos nas expressões do ultraconservadorismo, os princípios do Código de Ética do/a assistente social constituem normas jurídicas e, como tal, podem impor obrigações e direitos para a profissão. Ou seja, "[...] o princípio é por definição "mandamento nuclear de um sistema", definindo assim a lógica do sistema normativo, conferindo-lhe a devida harmonia e coerência" (BARROCO; TERRA, 2012, p. 128). Se assim não o fossem, os princípios funcionariam como meros parâmetros ideológicos, destituídos de força sancionatória.

A dimensão ético-política do Serviço Social, sobressalente no Código de Ética de 1993, reconhece pela primeira vez, no decurso histórico-profissional do Serviço Social, as dominações, opressões e explorações sexistas, patriarcais, homo-lebo-bi-trans-fóbicas e racistas. Ainda há muito por lutar. Exemplo disso é a necessidade de se considerar impreterível as discussões sobre gênero e sexualidade no espaço universitário/acadêmico, nos espaços sócio-ocupacionais ocupados pela categoria profissional, em fóruns, encontros, reuniões, congressos, entre outros espaços ocupados pelo Serviço Social.

A partir de 1993 o Conselho Federal de Serviço Social (CFESS), bem como os Conselhos Regionais de Serviço Social (CRESS) colocam em pauta as discussões sexuais e de gênero. Há de se convir que o movimento estudantil, através da Executiva Nacional dos Estudantes de Serviço Social (ENESSO), contribuíram significativamente para a inserção do tema da diversidade sexual e de gênero na agenda política do Serviço Social. Certamente, é oportuno entender que "As questões e temáticas são inseridas na agenda profissional, porque existem na realidade e adentram o universo do Serviço Social, ao se transformarem em demandas que requisitam respostas profissionais" (SANTOS, 2016, p. 33-34). Numa perspectiva de luta e resistência ao ultraconservadorismo, pretendendo-se materializar os princípios existentes em seu Código de Ética e PEP, o Serviço Social brasileiro apresenta, assim, uma agenda de lutas que fortalece e amplia a defesa da diversidade sexual e de gênero.

À guisa de exemplo, tem-se em julho de 2006, aprovada durante $034^{\circ}$ Encontro Nacional CFESS-CRESS, a Campanha pela Livre Orientação e Expressão Sexual O Amor fala todas as línguas - assistente social na luta contra o preconceito (CONSELHO FEDERALDE SERVIÇO SOCIAL, 2007). A campanha foi efetuada com a finalidade de embrandecer a sociabilidade e a categoria profissional para o reconhecimento do respeito à diversidade humana por meio de uma discussão conceitual e de uma análise crítica fundamentada na igualdade, liberdade e justiça social balizadas no Código de Ética do/a assistente Social. A campanha supracitada foi inovadora, marcando a defesa e a ampliação de direitos da população LGBT,

Temporalis, Brasília (DF), ano 19, n. 38, p. 180-195, jul./dez. 2019. | ISSN 2238-1856 


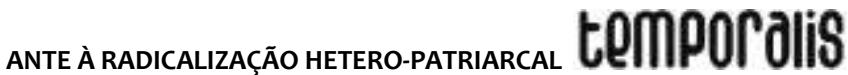

uma população historicamente aviltada nas suas condições de existência. Desta campanha, ocorreram discussões internas à diretoria do CFESS a respeito da diversidade sexual, sendo levadas, posteriormente, aos conselhos regionais.

Visando-se a construção de um espaço com a população LGBT, realizaram-se em 2006, durante $02^{\circ}$ Fórum Social Brasileiro no Recife (PE), duas oficinas temáticas sobre $A$ necessidade histórica da liberdade de orientação e expressão sexual. Foram promovidas, no mesmo ano, mesas temáticas nos cinco encontros descentralizados do Conjunto CFESS/CRESS. Ademais, a grandiosa aprovação da Resolução CFESS n. 489/2006 (CONSELHO FEDERALDE SERVIÇO SOCIAL, 2006)corroborou para determinar diretrizes que vedam, no exercício profissional do/a assistente social, estereótipos, juízos de valor, condutas e comportamentos preconceituosos, moralizantes ou discriminatórios por questões de orientação e expressão sexual por pessoas do mesmo sexo.

Ano por ano, além de manifestações públicas em defesa dos direitos da população LGBT e das mulheres, no Encontro Nacional CFESS/CRESS de 2009 (CONSELHO FEDERALDE SERVIÇO SOCIAL, 2009), o Conjunto CFESS/CRESS se posiciona em defesa da descriminalização do aborto e aprova em 2010 a sua legalização. O Serviço Social passa a incorporar, não sem tensões, uma das bandeiras de luta mais polêmicas dos movimentos feministas, reconhecendo, então, que a criminalização do aborto reforça a promoção das desigualdades de gênero, raça/etnia e classe.

A Associação Brasileira de Ensino e Pesquisa em Serviço Social (ABEPSS) incorpora, também, as pautas relativas à diversidade humana. Exemplo disso é a criação em 2010 do Grupo Temático de Pesquisa (GTP) em Serviço Social, Relações de Exploração/Opressão de Gênero, Raça/Etnia, Geração, Sexualidades. O GTP percebe que as dimensões da exploração e opressão são estruturantes da sociabilidade do capital e intrinsecamente imbricadas à dimensão de classe. No entanto, a ementa do GTP não parte da concepção de consubstancialidade e coextensividade das relações de gênero, raça/etnia e classe, mas sim da noção interseccional entre tais categorias. O GTP, para mais, reiterou a importância de serem ofertadas disciplinas obrigatórias que tratem sobre essas temáticas na graduação em Serviço Social, antes ou concomitante à inserção dos/as discentes no estágio supervisionado (QUEIROZ et al., 2014).

A Resolução CFESS n. 615/2011 (CONSELHO FEDERALDE SERVIÇO SOCIAL, 2011), por seu turno, veio assegurar o direito à diversidade de gênero. Nesse sentido, os/as assistentes sociais travestis e transexuais tiveram o direito à inclusão e ao uso do nome social nos documentos de identidade profissional assegurados por essa resolução. Em 2013, tem-se a campanha Nem rótulos, nem preconceito. Quero respeito, realizada pelo CFESS, almejandose reafirmar a Resolução CFESS n. 615/2011 e o compromisso ético-político da profissão com a garantia da livre expressão sexual e da identidade de gênero.

A ENESSO, mobilizando-se em defesa da diversidade humana e contrária às formas de opressão e discriminação, lança em 2013 a cartilha ENESSO Feminista. A ENESSO delibera, então, a sua participação nos fóruns e conferências do Serviço Social, no Encontro Nacional Universitário de Diversidade Sexual (ENUDS), em espaços de atuação política (tais como: Marcha Mundial das Mulheres, Encontro de Mulheres Estudantes da UNE, Marca das 
Vadias, Movimento LGBT, entre outros). Delibera-se também o apoio às políticas que garantam direitos sexuais e reprodutivos para as mulheres, a defesa à criminalização da homofobia, à descriminalização e à legalização do aborto.

Não se pode esquecer da elaboração e lançamento no ano de 2016 da série Assistente Social no combate ao preconceito. Até o presente momento, esta série reúne cinco temáticas. A saber: 1) o que é preconceito; 2) o estigma do uso de drogas; 3) racismo; 4) transfobia; 5) xenofobia. Além disso, elabora-se em 2018 a Resolução CFESS n. 845/2018 (CONSELHO FEDERALDE SERVIÇO SOCIAL, 2018) que dispõe sobre a atuação profissional no que tange ao processo transexualizador. Além de lutar pela despatologização da transexualidade, esta resolução preconiza que, no âmbito dos espaços sócio-ocupacionais, o/a assistente social deve promover uma cultura de respeito à diversidade de expressão e identidade de gênero, rejeitando-se quaisquer avaliações ou modelos corretivos que reforcem preconceitos e discriminações.

A articulação do CFESS com o Instituto em Defesa da Diversidade Afetivo-Sexual (DIVAS), com os sujeitos políticos atuantes na Liga Brasileira de Lésbicas (LBL), com a Articulação Brasileira de Lésbicas ( $A B L)$ e com a Associação Brasileira de Lésbicas, Gays, Bissexuais, Travestis e Transexuais (ABLGBT), representa uma das conquistas do Serviço Social na resistência e enfrentamento ao ultraconservadorismo. É também de grande valia a vinculação do Serviço Social com os movimentos feministas para o entendimento do sentido sócio-histórico da emergência e institucionalização da profissão, sua inserção na divisão sexual do trabalho, para o fortalecimento dos processos de radicalização da democracia, para o desvelamento crítico das opressões e explorações hetero-patriarcais, bem como para a formação de uma consciência feminista, na luta pela igualdade e liberdade substantivas.

Verifica-se, deste modo, que a agenda política do Serviço Social alinha-se ao compromisso com os princípios e valores éticos que balizam a atuação dos/as assistentes sociais. Isto implica na reafirmação da intenção de rompimento e a recusa de ações conservadoras e/ou tradicionais as quais o Serviço Social se vinculara em seu decurso histórico-profissional. Um dos desafios colocados ao Serviço Social diz respeito ao fato de que o mesmo não se encontra fora ou imune às armadilhas do ultraconservadorismo, sobretudo em sua dimensão hetero-patriarcal.

A promoção de uma indignação ética pela categoria profissional é salutar para a transgressão da profissão a essas ingerências. Em antagonismo às ingerências heteropatriarcais e suas inflexões, é cabível no interior do Serviço Social brasileiro, portanto, "reconhecer que o esclarecimento desta categoria do possível e de sua conexão com o fim desejado não torna fácil, por si mesma, a tarefa de "dar passos na direção certa" (TONET, 2016, p. 37).

\section{À GUISA DE CONSIDERAÇÕES FINAIS}

As relações cis-heteropatriarcais de gênero põem em tela a produção e reprodução do machismo, das relações de poder, do preconceito, da discriminação, etc. Nas singularidades do quinto país mais violento contra as mulheres (Brasil), revigora-se a existência de binarismos (homem/mulher, masculino/feminino) sustentados na 


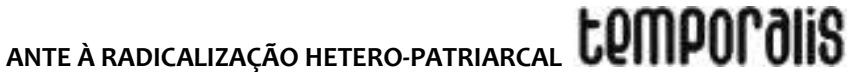

cisgeneridade como um paradigma normativo de gêneros coerentes, limitado a um número de dois.

Assim, esta investigação partiu da compreensão de que as relações sociais formam um nó entre as categorias gênero (e sexualidade), raça e classe, não podendo dissociá-los ao nível das práticas sociais. No entanto, apenas para uma análise sociológica é que essas relações podem ser sequenciadas (KERGOAT, 2012). Esta pesquisa se deteve, portanto, à análise das relações hetero-patriarcais de gênero superdimensionadas face aos antagonismos atuais da sociabilidade do capital articulados ao conservadorismo. Dito isto, as relações heteropatriarcais de gênero (como aqui se defende), raça/etnia e classe não compõem relações interseccionais, posto que não estão separadas. Constituem, todavia, uma unidade dialética, uma vez que são relações consubstanciadas na sociabilidade hetero-patriarcalracista-capitalista.

Em que pesem as modulações violentas do patriarcado, do sexismo, do machismo, do racismo, do etnocentrismo, da LGBTfobia, os feminismos constituem resistência. Na luta por equidade e justiça social nas esferas econômica, social, política, cultural, ética, moral, estética, etc., as estratégias de resistência são materializadas através dos movimentos e organizações de mulheres, os movimentos feministas, os coletivos feministas, dentre outros.

A dimensão ético-política do Serviço Social reafirma, nessa perspectiva, valores, princípios, normas morais, direitos e deveres que, por meio do Código de Ética do/a Assistente Social, reconhecem as relações sociais de gênero, raça/etnia e classe. Dito de outro modo, o reconhecimento da consubstancialidade e coextensividade dessas relações é conditio sine qua non para que a profissão dê passos na direção de sucessivas aproximações com a realidade e suas múltiplas determinações. Pretendendo-se materializar os princípios existentes em seu Código de Ética, é fundamental dar atualidade à intenção de ruptura do Serviço Social brasileiro com a cultura e ideologia ultraconservadoras, sobretudo no que tange ao apartheid sexual e de gênero.

Desta forma, sendo os gêneros e as sexualidades categorias existentes na realidade social brasileira e expressões da questão social, posto que o Brasil é o país que mais mata a população de travestis e transexuais, e o quinto mais violento contra as mulheres, é indiscutível a necessidade da incorporação da diversidade sexual e de gênero na agenda de luta do Serviço Social brasileiro, na formação acadêmico-profissional, nos espaços sócioocupacionais dos/as assistentes sociais. Enfim, é imprescindível a edificação de um caldo ideopolítico e teórico-crítico anti-conservador no ínterim da profissão a partir do compromisso e identidade da categoria profissional com o seu projeto emancipatório ético-político.

\section{REFERÊNCIAS}

ANDRADE, D. Dandara foi espancada até a morte em plena luz do dia e seus assassinos riam. Brasil de Fato, São Paulo, 10 mar. 2017. Disponível em: <https://www.brasildefato.com.br/2017/03/10/artigo-dandara-foi-espancada-ate-a-morteem-plena-luz-do-dia-e-seus-assassinos-riam/>. Acesso em: 20 fev. 2018. 
BARROCO, Maria L. S.; TERRA, Sylvia H. Código de Ética do/a Assistente Social Comentado. Conselho Federal de Serviço Social - CFESS (organizador). São Paulo: Cortez, 2012.

CONSELHO FEDERAL DE SERVIÇO SOCIAL. Resolução CFESS 845/2018, de 26 de fevereiro de 2018. Ementa: Dispõe sobre atuação profissional do/a assistente social em relação ao processo transexualizador. Brasília (DF), 2018.

CONSELHO FEDERAL DE SERVIÇO SOCIAL. Resolução CFESS N ${ }^{\circ}$ 615/2011, de 8 de setembro de 2011. Ementa: Dispõe sobre a inclusão e uso do nome social da assistente social travesti e do(a) assistente social transexual nos documentos de identidade profissional. Brasília (DF), 2011.

CONSELHO FEDERAL DE SERVIÇO SOCIAL. Conferências e deliberações do $35^{\circ}$ Encontro Nacional CFESS/CRESS, 2009.

CONSELHO FEDERAL DE SERVIÇO SOCIAL. Resolução CFESS N 489/2006, de 3 de junho de 2006. Estabelece normas vedando condutas discriminatórias ou preconceitos, por orientação e expressão sexual por pessoas do mesmo sexo, no exercício profissional do assistente social, regulamentando princípio inscrito no Código de Ética Profissional. Brasília (DF), 2006.

CFESS MANIFESTA. $\mathbf{O}$ amor fala todas as línguas. Assistente Social na luta contra o preconceito: campanha pela livre orientação e expressão sexual. Natal, ago. 2007. Disponível em: http://www.cfess.org.br/arquivos/CFESSMANIFESTAOAMORFALATODASASLINGUAS.pdf. Acesso em: 20 fev. 2018.

CISNE, M.; SANTOS, S. Feminismo, diversidade sexual e Serviço Social. São Paulo: Cortez, 2018. (Biblioteca Básica de Serviço Social; v. 8).

DELPHY, C. Patriarcado. In: HIRATA, H. et al. (Orgs.). Dicionário crítico do feminismo. São Paulo: Editor da Unesp, 2009.

ESCORSIM NETTO, Leila. O conservadorismo clássico. Elementos de caracterização e crítica. São Paulo: Cortez, 2011.

FOUCAULT, Michel. História da sexualidade. Vol. 1: A vontade de saber. 11. ed. Rio de Janeiro: Graal, 1988.

G1. BA ocupa $2^{\circ}$ lugar em crimes contra LGBTs, aponta relatório do Grupo Gay. G1, 25 jan. 2017. Disponível em: http://g1.globo.com/bahia/noticia/2017/01/ba-ocupa-2-lugar-emcrimes-contra-lgbts-aponta-relatorio-do-grupo-gay.html. Acesso em: 11 out. 2017.

IAMAMOTO, Marilda V. O Serviço Social na contemporaneidade: trabalho e formação profissional. 26. ed. São Paulo: Cortez, 2015.

INÁCIO, M. A emancipação das mulheres no projeto ético-político do Serviço Social: contribuições e dilemas das relações entre Marxismo e Feminismo. Tese de doutorado apresentada ao Curso de Doutorado do Programa de Pós-Graduação em Serviço Social, 


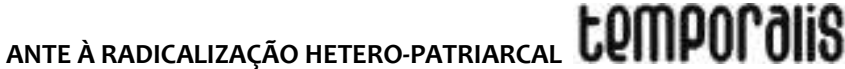

da Universidade Federal de Pernambuco, em 2013. Disponível em:

<https://repositorio.ufpe.br/bitstream/123456789/11456/1/TESE\%20_\%20MIRIAM\%20\%20DE \%20OLIVEIRA\%2OIN\%C3\%81CIO.pdf>. Acesso em: 11 out. 2018.

KERGOAT, D. Se battre, disent-elles... Paris: La Dispute, 2012.

LIMA SOBRINHO, Jodeylson Islony; LIMA, Rita de Lourdes de. Os desdobramentos do ethos idealista-formal no trabalho dos/as assistentes sociais. Temporalis, v. 18, n. 36, p. 28-44, 2018.

MARX, K.; ENGELS, F. A ideologia alemã. São Paulo: Expressão Popular, 2009.

NETTO, J. P. Ditadura e Serviço Social: uma análise do Serviço Social no Brasil pós-64. São Paulo: Cortez, 2015.

OSTERNE, M.; BRASIL, G.; ALMEIDA, R. A produção do conhecimento nas Ciências Sociais e a provisoriedade da realidade material e simbólica. Serviço Social \& Sociedade, São Paulo: Cortez, n. 113, jan./mar., 2013. Disponível em:

http://www.scielo.br/scielo.php?script=sci_arttext\&pid=S0101-66282013000100007.

Acesso em: 20 fev. 2018.

PAINS, Clarissa. 'Menino veste azul e menina veste rosa', diz Damares Alves em vídeo. 0 Globo, 3 jan. 2019. Disponível em: https://oglobo.globo.com/sociedade/menino-veste-azulmenina-veste-rosa-diz-damares-alves-em-video-23343024. Acesso em: 20 fev. 2019.

PAVANELI, Aline. 'Quem define gênero é a natureza', diz futuro ministro da Educação. G1, 26 nov. 2018. Disponível em: https://g1.globo.com/pr/norte-

noroeste/noticia/2018/11/26/quem-define-genero-e-a-natureza-diz-futuro-ministro-daeducacao.ghtml. Acesso em: 20 fev. 2019.

PITASSE, Mariana. Marielle Franco: "Ser mulher negra é resistir e sobreviver o tempo todo". Brasil de Fato, São Paulo, 15 mar. 2018. Disponível em:

https://www.brasildefato.com.br/2018/03/15/marielle-franco-or-ser-mulher-negra-eresistir-e-sobreviver-o-tempo-todo/. Acesso em: 20 fev. 2018.

QUEIROZ, F. et al. Grupo temático de pesquisa Serviço Social, Relações de Exploração/Opressão de Gênero, Raça/Etnia, Geração, Sexualidades: breve históricos e desafios. Temporalis, Brasília (DF), ano 14, n. 27, p. 233-241, jan./jun. 2014.

SANTOS, S. Ética em Movimento: curso de capacitação para agentes multiplicadores/as. Brasília: CFESS, 2016. (Ética e direitos humanos, Módulo 3).

SENADO NOTÍCIAS. Série especial da Rádio Senado trata da violência que ainda afeta as mulheres. Senado Notícias, 06 mar. 2018. Disponível em:

https://www12.senado.leg.br/noticias/audios/2018/03/serie-especial-da-radio-senado-tratada-violencia-que-ainda-afeta-as-mulheres. Acesso em: 15 out. 2018.

TONET, Ivo. Educação contra o capital. 2. ed. São Paulo: Instituto Lukács, 2016. 
UOL. Bolsonaro fala em combater ideologia de gênero; veja íntegra do discurso. UOL, Brasília, 01 jan. 2019. Disponível em: https://noticias.uol.com.br/politica/ultimasnoticias/2019/01/01/bolsonaro-fala-em-combater-ideologia-de-genero-veja-integra-dodiscurso.htm. Acesso em: 20 fev. 2018. 